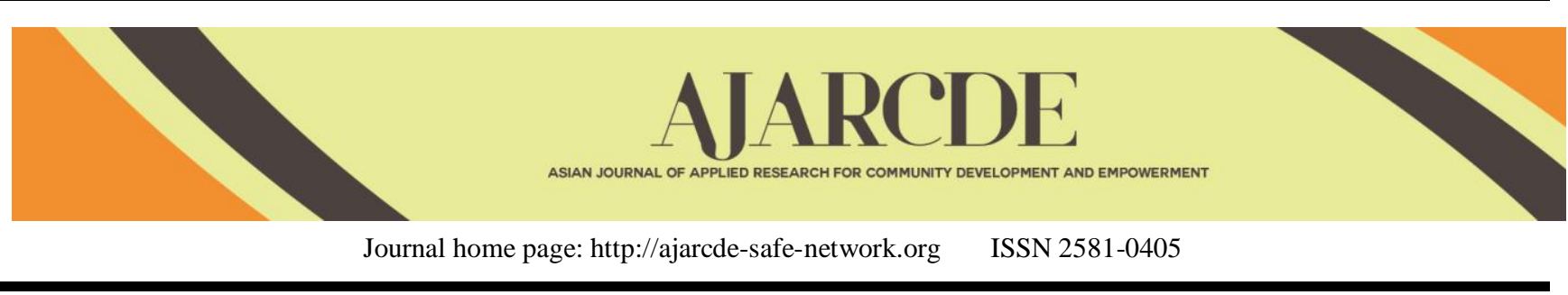

\title{
Compensation Management and Employee Motivation of Kunming Haitian Hotel
}

\author{
Zhang Lu and Prapatsorn Kittimanorom ${ }^{1}$ \\ ${ }^{I}$ Master of Business Administration, Rajapruk University. Thailand \\ *Corresponding author: poopleponpae@gmail.com
}

\section{ARTICLE INFO}

Article History:

Received: July 3, 2019

Final Revision: November 14, 2019

Available Online: December 13, 2019

\section{KEYWORDS}

The Compensation management, Employees

Motivation.

\section{CORRESPONDING AUTHOR}

*E-mail: poopleponpae@gmail.com

\section{A B S T R A C T}

The objective of this study was to investigate the compensation management, to study employees' motivation of Kunming Haitian Hotel, and to study the relationship of the compensation management and employees' motivation of the Kunming Haitian Hotel. The research instrument was the questionnaire. Data collected were analyzed through frequency, percentage, mean, standard deviation and Pearson's correlation coefficient. The sampling of this study was 80 individuals, those gender of female, aged between 26-35 years, graduated with high school, duration of employee 1-5 years, monthly income 3,001-4,500 Yuan. The analytic results of the compensation management and employee motivation of Kunming Haitian Hotel, with mean score of 3.65 was at agreeing to lowest mean scores as follows, the overall was found that the respondents gave importance to level of compensation management was at agreeing, rank first leasers was strategic compensation model, broadband pay model, the comprehensive compensation model was at agree, respectively. In terms of employee motivation, overall the respondents were at agreeing, with a mean score of 3.66. The factors were ranked from highest to lowest mean scores as follows: power, achievement, and affiliation at low level respectively. The results of hypothesis testing showed that the compensation management and employee motivation of the Kunming Haitian Hotel was a strong positive. The statistic significant was .05

\section{INTRODUCTION}

Truism Industry, is also facing fierce competition and challenges. On the one hand, the continuous pursuit of spiritual living standards in recent years has made the tourism industry extremely prosperous. With the continuous development of the tourism industry, various types and scales of hotels supported by the tourism industry have been built successively, and the construction of hotels of different sizes and types has been built. The competition in the industry has been further aggravated. The increase in hotel entities reflects the booming development of the hotel industry to a certain extent, which directly leads to an increase in the demand for hotel employees. Although on the surface, hotel employees have more choices in employment, but to a certain extent The turnover rate and turnover rate of hotel staff have continued to rise, and the turnover rate of hotel staff in China has remained high. At the same time, some high-level international hotel groups have joined the hotel industry. Competition in China in recent years, which has The excavation of high-level human resources with practical experience has become another important reason for the loss of hotel staff in China. According to the statistics of national star-rated hotels published by the National Tourism Administration, it can be seen from the analysis of the results that from 2009 to the end of 2013, although the number of star-rated hotels in the country has been reduced, the number of five-star hotels has become obvious [1].

The increase has increased from 509 to 739 , an increase of $45.19 \%$; the number of four-star hotels is also slowly increasing, from 1984 in 2009 to 2013, to 2361, with a growth rate of $19.00 \%$; With the intensification of market competition and the existence of management problems, the number of star-rated hotels has been significantly reduced. Taking two-star hotels as an example, the number of two-star hotels in 2009 was 5,375, which is available in 2013. The number of hotels has decreased to 2,831, a decrease of $89.86 \%$, and it can be seen from the statistics of the hotel staff in the National Star Tourism Statistics Bulletin of 2011-2013 that among the hotel employees, The number of employees with college education or above has increased year by year, and the proportion has increased from $20.79 \%$ to $21.55 \%$. Among the hotel employees, the number of employees in fivestar hotels continues to increase. Especially five-star hotel employees in the number of employees have a college education is the fastest growing, these show a company's human resources and the development of high-quality and competitive advantages are inseparable. On the other hand, in the process of human resource management, it is also very important for the management of compensation, and involves many aspects, but through research on the human resources management of some of our existing hotels, the management of the hotel is on the hotel. 
Therefore, the researcher an interested is studying focuses on the compensation management and employee motivation of Kunming Haitian Hotel, that affect to human resources management is not highly valued, plays a very limited role in the daily management of hotels. These have led to insufficient attention to the hotel's compensation management and increased employee turnover. Another important reason. At present, Kunming Haitian Hotel still implements the post salary system, does not establish a true modern salary management system, and lacks effective incentives for employees. This paper studies the problems existing in the daily salary management of Kunming Haitian Hotel, and finds out the causes of the problems, and finds some countermeasures to provide some targeted guidance for the future salary management activities of Kunming Haitian Hotel.

\section{MATERIALS AND METHODS}

\subsection{Population and sample}

In this study, Kunming Haitian Hotel. Selected as the target group. The company is a typical manufacturing industry. It also faces typical development issues. It is fully in line with the subject of the study. The company has a total of 100 employees and managers. The researchers used the sample scales of [2]. The sample size were 80 Samples.

\subsection{Research Instrument}

This study used a questionnaire survey method to investigate There is a relationship between compensation management and employee motivation of Kunming Haitian Hotel. The questionnaire design is divided into fourth parts. The first part is the demographics of the employees. The design of the problem is closed and has a choice of answers. The second part is the compensation management level. The third part of the Employee motivation level. The fourth part is the relationship between compensation management and employee motivation of Kunming Haitian Hotel. The questionnaire is divided into two areas: individual compensation management and employee motivation are designed as Level 5 answers [3]. 1 = very disagree, 2 = disagree, $3=$ neutral, $4=$ agree, $5=$ strongly agree, all questions in the questionnaire will be fixed after the professional has conducted a reliability effectiveness test. This process ensures that all issues are valid and reliable.

\subsection{Data Analysis}

Descriptive statistical analysis was used to describe the level of compensation management and employee motivation of Kunming Haitian Hotel. These data are described by frequency, percentage, average and standard deviation. The relationship between compensation management and employee motivation of Kunming Haitian Hotel. There was use Pearson Product Moment Correlation Coefficient.

\section{RESULT AND DISCUSSION}

\subsection{The Opinion of Compensation Management}

Table 1. Mean and Std. Deviation of Compensation Management of Kunming Haitian Hotel (Overall)

\begin{tabular}{lcccl}
\hline Compensation Management & $\bar{X}$ & SD & Level & Rank \\
\hline $\begin{array}{l}\text { 1.Strategic compensation } \\
\text { model }\end{array}$ & 3.75 & 0.84 & Agree & 1 \\
$\begin{array}{l}\text { 2.Comprehensive } \\
\text { compensation model }\end{array}$ & 3.59 & 0.85 & Agree & 3 \\
3.Broadband pay model & 3.64 & 0.83 & Agree & 2 \\
\hline Total & $\mathbf{3 . 6 5}$ & $\mathbf{0 . 8 2}$ & Agree & \\
\hline
\end{tabular}

Table 1 the overall was found that, the respondents gave importance to level of compensation management was at agree $\left(\mathrm{X}^{-}=3.65, \mathrm{SD}=0.82\right)$, rank first leasers was strategic compensation model was at agree $\left(\mathrm{X}^{-}=3.75, \mathrm{SD}=0.84\right)$, rank second leasers was broadband pay model was at agree $\left(\mathrm{X}^{-}=3.64\right.$, $\mathrm{SD}=0.83)$, the lowest rank leaders was comprehensive compensation model was at agree $\left(\mathrm{X}^{-}=3.59, \mathrm{SD}=0.85\right)$.

\subsection{The Opinion of Employee Motivation}

Table 2. Mean and Std. Deviation of Employee Motivation of Kunming Haitian Hotel (Overall)

\begin{tabular}{lcccc}
\hline Employee Motivation. & $\bar{X}$ & SD & Level & Rank \\
\hline 1.Achievement & 3.78 & 0.90 & Agree & 2 \\
2.Affiliation & 3.68 & 0.96 & Agree & 3 \\
3.Power & 4.04 & 0.47 & Agree & 1 \\
\hline Total & 3.66 & 0.98 & Agree & \\
\hline
\end{tabular}

Table 2 the overall was found that, the respondents gave importance to level of employee motivation was at agree $\left(\mathrm{X}^{-}=\right.$ $3.66, \mathrm{SD}=0.98)$, rank first leaders was power was at agree $\left(\mathrm{X}^{-}=\right.$ $4.04, \mathrm{SD}=0.47)$, rank second leasers was achievement was at agree $\left(\mathrm{X}^{-}=3.78 \mathrm{SD}=0.90\right)$, the lowest rank leaders was affiliation was at agree $\left(\mathrm{X}^{-}=3.68, \mathrm{SD}=0.96\right)$.

\subsection{Hypothesis test results}

Table 3. Summarize the relationship between Compensation Management and Employee Motivation

\begin{tabular}{|l|c|c|c|}
\hline \multirow{2}{*}{$\begin{array}{l}\text { Compensation } \\
\text { Management }\end{array}$} & \multicolumn{3}{|c|}{ Employee Motivation } \\
\cline { 2 - 4 } & $\begin{array}{c}\text { Achievement } \\
\text { positive } \\
\text { relationship }\end{array}$ & $\begin{array}{c}\text { Affiliation } \\
\text { positive } \\
\text { relationship }\end{array}$ & $\begin{array}{c}\text { Power } \\
\text { positive } \\
\text { relationship }\end{array}$ \\
\hline $\begin{array}{l}\text { Strategic } \\
\text { compensation }\end{array}$ & $.65^{* *}$ & $.68^{* *}$ & $.68^{* *}$ \\
\hline $\begin{array}{l}\text { Comprehensive } \\
\text { compensation }\end{array}$ & $.64^{* *}$ & $.61^{* *}$ & $.64^{* *}$ \\
\hline Broadband pay & $.78^{* *}$ & $.67^{* *}$ & $.65^{* *}$ \\
\hline Total & $.69 * *$ & $.68 * *$ & $.66^{* *}$ \\
\hline
\end{tabular}

**. Correlation is significant at the .01 level (2-tailed).

Table 3 shows that at strong positive correlation between compensation management and achievement $(r=0.69)$, there was at positive correlation between performance management and affiliation $(\mathrm{r}=0.68)$, there was at strong positive correlation between performance management and power $(r=.66)$. 


\subsection{Discussions}

It is found that the most of respondents were female; were age 26-35 years old; the main force of the education background high school. Duration of employment 1 to 5 years, monthly income were 3,001-4500 Yuan.

Compensation management was at agree, rank first leasers was strategic compensation model was at agree, rank second leasers was broadband pay model was at agree, the lowest rank leaders was comprehensive compensation model was at agree. Strategic compensation model was at agree, rank first leader was the company's distribution mechanism is keeping to the principle of fairness impartiality and openness was at agree, rank second leader was the company's compensation system can attract excellent talents was at agree, the lowest rank leader was the current salary can reflect your personal value was at agree. Comprehensive compensation model [4]

This paper provides a comprehensive model of an agent's behavior in response to multiple sales management instruments, including compensation, recruiting termination, and training. The model takes into account many of the key elements that constitute a realistic sales force setting: allocation of continuous effort; forward-looking behavior; present bias; effectiveness of training; and employee selection and attrition. The paper provides insights into the way that employee training, recruiting policies, and various compensation components affect both the selection and performance of heterogeneous sales agents. In addition, the paper provides two key methodological contributions. First, we provide identification results for dynamic models with continuous and unobserved choice variables, which arise in many empirical applications but are often ruled out due to theoretical intractability. Second, we consider a hyperbolic discounting model as well as an exponential discounting model and provide conditions under which each model is identified. The key to identification is that, under a multi-period nonlinear incentive scheme, an agent's proximity to a goal affects only future payoffs in non-pecuniary periods, providing exclusion restrictions on the current payoff employees can get spiritual satisfaction from the work itself and the company was at agree, rank second leader was salary can improve the quality of life, the business benefits are closely related to employee salary was at neutral. Broadband pay model gave importance to the level of the Broadband pay model was at agree, the salary is higher than the industry. The salary return is fit to your hard work and your position according to the specified time, the company's salary payment is accurately and timely was at neutral.

\section{CONCLUSION}

The Company maintain of the strategic compensation model broadband pay model and comprehensive compensation model was at agree. the company's distribution mechanism is keeping to the principle of fairness impartiality, the company's compensation system can attract excellent talents the current salary can reflect your personal value and broadband pay model was at agree, the salary is higher than the industry The salary return is fit to your hard work and your position was at agree, according to the specified time, the company's salary payment is accurately and timely was at neutral. Compensation management and motivation has been observed by scholars and enunciated to be very fundamental to an organization and in enhancing its performance.
For an organization to stand a test of time and to enjoy competitive advantage in a competing environment, effective compensation strategy and for motivational factors must be put in place to attract, retain and develop skillful employees that will be dedicated, committed and endeared to the achievement of the organizational set goals. Compensation management and motivation as a veritable instrument in the hand of managers can be adopted to reduce absenteeism, labor turnover, industrial unrest and so on within the organization thus improvement on organizational performance and employees performance is guaranteed that lead to competitive advantage. However, for any organization to enjoy sustainability and remain on top, adequate remuneration and motivational process must be entrenched to the philosophy of the organization that will be of great interest to both the employees and the organization. This can be achieved through periodical review of the remuneration package by the organization.

Employee Motivation the respondent's opinion of affiliation. gave importance to the level of the affiliation was at agree, the salary level matches your position employees have the same training opportunities was at agree, the company's method of rating outstanding employees is reasonable was at agree. This implies that the respondents were adequately qualified to provide reliable data in regard to the study variables. Further interpretation pertaining to the education level of the respondents is that the largest cluster of personnel is educated up to graduate level and thus presenting an opportunity to embrace organizational compensation management and employee motivation in Haitian Hotel.

This suggests that organizational compensation management positively influenced organizational employee motivation in Haitian Hotel. The study recommends the need for additional studies to be conducted in this area of study, however particular consideration to be given to all sectors of the economy. It will also be interesting to carry out a study in a public organization setting so as to be able to establish if indeed the same findings will be achieved. More studies regarding the compensation and employee motivation has been shown to be an important aspect of a firm, as it can, and does affect employee's behaviors, motivation and values. Organizational performance management system creates career paths for employees as well as groupings of people who remain in the firm for a long enough time for a company culture to form. This outlook suggests that firms can implement such management practices that foster job security and internal career development in order to keep turnover low and maintain those social phenomena that comprise organizational culture (values, beliefs, norms, assumptions) within the organization, and therefore forming a strong organizational culture.

In this very competitive environment, any business company will only survive and flourish if only it's capable to discover new products since creativity and performance is inseparable. Greater levels of creativity lead to much innovation. Growing an organizational culture that ignites and promotes creativity and innovation is very essential for organizations which are in quest of competitive advantage. Organizations should develop a culture in order to use it as special unique competitive advantage. Organizational culture triggers innovations, hence producing better products and services. Organizational culture balances the internal and external operations, enabling the organization to realize new and profitable business arenas. For an 
organization to effectively utilize its culture corporately, the organization should research and study to understand its culture The compensation management should be improved in Kunming Haitian Hotel because it boosts organizational performance. Specifically, should motivate its employees to strive to achieve the company's set goals and objectives also cultivate a compensation management in which employees are free and conversant on how the company functions, mission, vision and objectives that guide all stakeholders. should review and redesign good ethical codes of conduct. These are organizational set of principles and policies which guides the inter relationship between the employees. The company is also required to motivate employees to have a sense of belonging which boosts their devotion to work because this will positively encourage effective organizational performance.

\section{ACKNOWLEDGMENT}

I want to thanks those who contributed and helped make this research possible. First of all, I would like to express my heartfelt thanks to Dr.Prapatsorn Kittimanorom for her valuable advice, encouragement and help in completing this research project, as well as her love for education. In addition, I am grateful for Assoc. Prof. Sasanant Vivadhnajat MBA Director, Rajapruk University and others person for suggestions and all their help, Dr.Yootanart Boonyachai.

\section{REFERENCE}

[1]. China National Tourism Administration.(2013). The statistics of national star-rated hotels published.

[2]. Krejcie, R. V. \& Morgan, D. W. (1970). ). Determining Sample Size for Research Activities.

[3]. Likert, R. (1932). A technique for the measurement of attitudes. Archives of Psychology, 1-55. Referred in Warmbrod, J.R. (2014). Reporting and Interpreting Scores.

[4]. Doug J. Chung, Byungyeon Kim, and Byoung G. Park (2019). The Comprehensive Effects of Sales Force Management: A Dynamic Structural Analysis of Selection, Compensation, and Training. Article. Business Research for Business Leaders publishing.. 